\title{
Combined Kinetic Analysis of Solid-State Reactions: The Integral Method
}

\section{(ICKA)}

\author{
M.D. Casal and Gregorio Marbán*
}

Instituto de Ciencia y Tecnología del Carbono (INCAR-CSIC) - c/Francisco Pintado Fe 26, 33011-Oviedo (Spain). Tel. +34 985119090; Fax +34985297662

\begin{abstract}
In this work, we propose the first Integral method for the Combined Kinetic Analysis (ICKA) of solid-state reactions typically performed in a thermogravimetric analyzer. The ICKA method prevents the systematic inaccuracies inherent to all the differential methods, including the standard CKA method. Two main achievements have been made for implementing the method: (1) the most accurate approximation for the general temperature integral yet developed, and (2) a general integral form of the kinetic model of the type $g(\alpha)=$ $(a b c Z)^{-1}\left[1-\left(1-\alpha^{a}\right)^{b}\right]^{c}$, where $Z$ is a parameter evaluated together with the preexponential factor and $a, b$ and $c$ are fitting parameters. This expression allows any known kinetic model to be exactly or very closely reproduced. Together, the two developments yield an equation for the conversion, $\alpha$, that has been successfully fitted to simulated conversion values of single-step reaction processes following different kinetic models. The curve fitting resulted in the same values of the kinetic and model parameters as those from which the simulated conversion curves were originally built, proving the validity of the ICKA method.
\end{abstract}

Keywords: Thermogravimetric analysis, exponential integral, conversion function, combined kinetic analysis, integral method

\footnotetext{
• Corresponding author: greca@incar.csic.es
} 


\section{Introduction}

The kinetics of solid-state reactions have been extensively researched by means of thermogravimetric analysis (TGA) [1-5], where the results come in the form of a curve relating the reacted fraction or conversion, $\alpha$, to the reaction time, $t . \alpha$ is evaluated from the weight evolution with time as:

$\alpha=\frac{w_{0}-w_{t}}{w_{0}-w_{f}}$

where $w$ indicates weight and the subscripts $0, f$, and $t$ are the initial time, final time, and time $t$, respectively. The fundamental kinetic equation for any solid-state process that can be reasonably approximated as single-step kinetics [3] can be written as:

$\frac{d \alpha}{d t}=A f(\alpha) e^{-E / R T}$

where $d \alpha / d t$ is the reaction rate $\left(\mathrm{s}^{-1}\right), A$ is the Arrhenius preexponential factor $\left(\mathrm{s}^{-1}\right), R$ is the universal gas constant $\left(8.314 \mathrm{~J} \mathrm{~mol}^{-1} \mathrm{~K}^{-1}\right), E$ is the activation energy $\left(\mathrm{J} \mathrm{mol}^{-1}\right), T$ is the absolute temperature (K) at a time $t(\mathrm{~s})$ and $f(\alpha)$ is the conversion function. $f(\alpha)$ is assumed to be constant for constant values of $\alpha$. In the words of Friedman [6], this is comparable to assuming that the chemistry of the process is independent of temperature, and is dependent only of the value of $\alpha$. For the thermogravimetric analysis, different heating pathways can be used, the most common ones being isothermal, linear heating, modulated temperature, and sample-controlled [3,7,8]. For evaluation of the kinetic triplet (activation energy, preexponential factor and conversion function), differential methods use the logarithmic form of equation (2) [6]. However, they are associated with certain systematic inaccuracy derived from the experimental data noise (a small error in the numerical differentiation of the conversion values produces a magnified error in the evaluation of the kinetic parameters) and 
from the need of establishing a proper baseline [3]. Integral methods overcome these disadvantages using the measured thermogravimetric data without differentiation and for this reason they are more commonly employed [9-13]. Unfortunately, for linear heating analysis, equation (2) cannot be analytically integrated. This situation is further complicated for some complex reactions, in which the following relationship among the preexponential factor and the temperature is known to be established:

$A=A_{0} T^{s}$

where $A_{0}$ is the temperature-independent preexponential factor $\left(\mathrm{s}^{-1} \mathrm{~K}^{-s}\right)$ and $s$ is an exponent that generally varies between -2.5 and 2.5 , depending on the type of reaction [14]. If equation (3) is taken into account, equation (2) can be integrated and the resulting equation conveniently rearranged to obtain the following expression:

$\ln (\beta)=\ln \left[\frac{A_{0}(E / R)^{s+1}}{g(\alpha)}\right]+\ln \left[p_{s}(x, s)\right]$

where $\beta$ is the linear heating rate $\left(\mathrm{K} \mathrm{s}^{-1}\right), x=E / R T$ and $g(\alpha)=\int_{0}^{\alpha} d \alpha / f(\alpha)$. In this equation, $p_{s}(x, s)$ is commonly known as the general temperature integral [15], taking the form:

$p_{s}(x, s)=\int_{x}^{\infty} \frac{e^{-x}}{x^{2+s}} d x$

A large number of approximations can be found in the literature for $s=0$ [13,16-21], though there are only a few that can be used for $\mathrm{s} \neq 0[18,20]$. One of the goals of the present work is to produce an accurate approximation for $p_{s}(x, s)$ that not only should be valid in the whole $s$ range but also should perform as well as the best standard approximations for $s=0$.

From equation (4) it can be seen that the temperature-independent preexponential factor cannot be independently evaluated unless the conversion function of the process under study, 
$f(\alpha)$, is previously known or, in other words, it belongs to the collection of known conversion functions $[1,4,22,23]$. Table 1 lists the most common kinetic models (conversion functions) described in the literature. In order to select the most appropriate kinetic model for the process under study among those indicated in Table 1, techniques such as the generalized master plots $[24,25]$ can be employed. This technique consists of determining the activation energy of the process by any standard model-free method and then using equation (6) to evaluate a normalized conversion function, $f(\alpha) / f(0.5)$ :

$\frac{f(\alpha)}{f(0.5)}=\frac{d \alpha / d t}{(d \alpha / d t)_{0.5}} \frac{e^{-E / R T}}{e^{-E / R T_{0.5}}}$

where the 0.5 subscript indicates values at $\alpha=0.5$. By comparing the experimental $f(\alpha) / f(0.5)$ values with those for known kinetic models one can eventually find the correct conversion function. This technique is useful to obtain the conversion function, and subsequently the preexponential factor, provided the experimental normalized conversion function coincides with that of any of the known theoretical kinetic models (Table 1). However, more often than not, this is not the case.

To overcome this limitation, some attempts have been made to obtain a universal expression for the conversion function based on a few empirical parameters. By selecting the proper values for such parameters, the general conversion function should be able to accurately match the most common kinetic models and, most importantly, when no known model can reproduce the values obtained with the empirical equation, this can help in the search for new kinetic models. There are two relevant equations proposed in the literature so far: the SestakBerggren equation [1] and the Cai-Liu equation [26]. Both of them can be represented by the following expression: 
$f(\alpha)=c \alpha^{m}(1-q \alpha)^{n}[-\ln (1-\alpha)]^{p}$

in which $q=1$ for the Sestak-Berggren equation [1], $q=1$ and $p=0$ for the truncated SestakBerggren equation used by Pérez-Maqueda et al. [7] and $p=0$ for the Cai-Liu equation [26]. The procedure to evaluate the values of activation energy and the unknown parameters of the universal conversion function is to introduce this in the Friedman equation [6] and perform the curve fitting by linear and/or nonlinear regression. This method is known as the combined kinetic analysis (CKA method) [7]. However, since no universal $f(\alpha)$ equation yet proposed can be analytically integrated to obtain $g(\alpha)$, the method should rather be called the differential CKA method, which implies the existence of the systematic inaccuracies inherent to all the differential methods. In the present work we propose the first integral CKA method $(I C K A)$, via the use of both a universal $f(\alpha)$ function that can be integrated to obtain a universal $g(\alpha)$ function, and an optimal approximation of the general temperature integral, $p_{s}(x, s)$.

\section{Theory of ICKA method}

In this work we propose the following universal conversion function:

$f(\alpha)=Z\left[1-\left(1-\alpha^{a}\right)^{b}\right]^{1-c}\left(1-\alpha^{a}\right)^{1-b} \alpha^{1-a}$

in which $Z, a, b$ and $c$ are parameters that depend on the kinetic model. This equation can be used to analytically obtain the integral form of the kinetic model:

$g(\alpha)=\frac{\left[1-\left(1-\alpha^{a}\right)^{b}\right]^{c}}{a b c Z}$

By replacing equation (9) in equation (4) and clearing $\alpha$, the following expression is obtained: 
$\alpha=\left\{1-\left[1-\left(\frac{a b c\left(Z A_{0}\right)(E / R)^{s+1}}{\beta} p_{s}(x, s)\right)^{1 / c}\right\}^{1 / b}\right.$

Equations (8), (9) and (10) are valid when $Z, a, b$ and $c$ all have values different from zero. Some limiting cases can also be covered by the method and are summarized in Table 2 .

As discussed later in this paper and summarized in Table 1, the limiting case that impacts a higher number of kinetic models is that in which $Z$ and $a$ are different from zero, $b=0$ and $c=1$. For this specific case, the equations for $f(\alpha), g(\alpha)$ and $\alpha$ become:

$f(\alpha)=Z\left(1-\alpha^{a}\right) \alpha^{1-a}$

$g(\alpha)=\frac{-\ln \left(1-\alpha^{a}\right)}{a Z}$

$\alpha=\left[1-\exp \left(-\frac{a\left(Z A_{0}\right)(E / R)^{s+1}}{\beta} p_{s}(x, s)\right)\right]^{1 / a}$

The integral CKA method (ICKA) consists of fitting either equation (10) or equation (13) to the data of the $\alpha v s$. $T$ curves for a discrete number of non-isothermal experiments in order to find the values of $E, Z A_{0}, a, b$ and $c$ [eq. (10)] or $E, Z A_{0}$ and $a$ [eq. (13)]. The value of $s$ might also be obtained from the fitting procedure if a value different from zero is suspected. To facilitate the curve fitting, a previous estimation of $E$ can be performed by any of the standard model-free methods. In this work, the curve fitting was performed by nonlinear regression analysis [27] with the Solver complement of Microsoft ${ }^{\circledR}$ Office Excel. Note that equation (10) can be used for any situation (including the limiting cases) provided the inverse values of the parameters (i.e., $1 / a, 1 / b$ and $1 / c)$ are optimized instead of the original parameters, so that 
division-by-zero errors are avoided during the calculations. It is also advisable to optimize the parameter $Z A_{0}$ as $\ln \left(Z A_{0}\right)$, in order to speed up the convergence process. The key premises for the application of this method are (i) an accurate approximation for the general temperature integral, $p_{s}(x, s)$, and (ii) the applicability of equations (9) or (12) to the known kinetic models. Both premises have been accomplished in the present work, as discussed below.

\section{Results and Discussion}

\subsection{Approximation of the general temperature integral, $p_{s}(x, s)$}

According to Starink [28], most of the solid-state reactions occur in the $15<x<60$ range, although, due to physical reasons it can be considered that a more extended range $(9<x<100)$ covers all the cases of practical significance. Our own calculations with data taken from the literature show the following $x$ ranges for different processes: $5<x<75$ for coal pyrolysis and combustion [29] and $20<x<80$ for biomass, plastic waste and oxalate pyrolysis [30-32]. Therefore, a high accuracy for the general temperature integral is required in the $5<x<100$ range. There are a number of approximations for $p(x)\left[=p_{s}(x, 0)\right]$ (Arrhenius integral) and most of them are based on the expression [13,16-19]:

$p(x)=\frac{e^{-x}}{x^{2}} h(x)$

where $h(x)$ is a mathematical expression that can be either exponential or rational [33,34]. In the simplest case, i.e., the Coats and Redfern method [13], $h(x)=1-2 / x$. Most of these approximations lose accuracy for small or large values of $x$ [28] or have a large number of coefficients, making the computation more complex.

Similarly to equation (14), the approximations for $p_{s}(x, s)$ take commonly the form: 
$p_{s}(x, s)=\frac{e^{-x}}{x^{2+s}} h_{s}(x, s)$

As commented above, few approximations of $p_{s}(x, s)$ can be found in the literature. The one recently released by Lin et al. [35] can be considered the most precise as compared to previous approximations $[15,17,20]$. It works in the ranges $4 \leq x \leq 200$ and $-2.5 \leq s \leq 2.5$, and has the structure of eq. (15), in which $h_{s}(x, s)$ is of the rational type and can be evaluated as:

$h_{s}(x, s)=\frac{a_{1} x+b_{1} s+c_{1}}{x+b_{2} s+c_{2}}$

where $a_{1}=0.00038236, \quad b_{1}=-0.98071110, \quad c_{1}=-1.96306291, \quad b_{2}=0.36195384 \quad$ and $c_{2}=1.47704119$. There are other mathematical expressions with a very slightly lower error than that obtained with these parameters, but they are only valid for $s=0$ [19]. Therefore, the five-parameters approximation by Lin et al. [35] will be used as reference in the present work. Following the nomenclature employed by the authors, it will be named as the Lin_New approximation. Here, we offer a more precise mathematical expression for the temperature integral with only four parameters:

$h_{s}(x, s)=\frac{x+b_{1} s+c_{1}}{x+b_{2} s+c_{2}}$

where $b_{1}=-0.05924479, c_{1}=0.62385968, b_{2}=0.92755595$ and $c_{2}=2.59746116$. Compared to other approximations, this equation is very precise in the $-2.5 \leq s \leq 2.5$ and $5 \leq x \leq 671$ ranges. It is named in this work as the CM approximation.

To check the accuracy of the CM approximation, the relative error was calculated as:

$\varepsilon=\frac{\left|p_{s}(x, s)-p_{s}(x, s)_{n u m}\right|}{p_{s}(x, s)_{\text {num }}} \times 100$ 
where $p_{s}(x, s)$ is the approximate value and $p_{s}(x, s)_{\text {num }}$ is the numerical value. Figure 1 shows the error produced by the CM approximation in the analyzed $x$ range for different values of $s$. A remarkably low error is always obtained for $\mathrm{x} \geq 5$. Note that the solution for $\mathrm{s}=-2$ is exact $(\varepsilon=0)$. The plot for $\mathrm{s}=0$ in Figure 1 also offers a comparison with other approximations, only valid for this specific s value, some of which have been widely employed in solid-state kinetics analysis (e.g., the Doyle approximation [36] used in the Flynn-Wall-Ozawa method $[9,10]$ or the Coats-Redfern approximation [13]). The CM approximation compares favorably with all previous approximations, except for the Han approximation [19], which is very slightly more precise for $x \geq 8$.

Figure 2 shows a comparison of errors between the Lin_New and CM approximations. The maximum error in the corresponding $x$ interval $\left(\varepsilon_{\max }\right)$ is used for the comparison. The $\mathrm{CM}$ approximation is more precise than the Lin-New approximation within the following ranges: $1 \leq x \leq 4 \quad\left(\varepsilon_{\max }<19 \%\right.$ vs. $\left.\varepsilon_{\max }<29 \%\right), 5 \leq x \leq 10 \quad\left(\varepsilon_{\max }<0.24 \%\right.$ vs. $\left.\varepsilon_{\max }<0.51 \%\right), \quad 10 \leq x \leq 15$ $\left(\varepsilon_{\max }<0.16 \%\right.$ vs. $\left.\varepsilon_{\max }<0.44 \%\right)$ and $15 \leq x \leq 671 \quad\left(\varepsilon_{\max }<0.09 \%\right.$ vs. $\left.\varepsilon_{\max }<0.23 \%\right)$. The only exception is at $x=4$ where the Lin_New approximation behaves slightly better $\left(\varepsilon_{\max }<0.5 \%\right)$ than the $\mathrm{CM}$ approximation $\left(\varepsilon_{\max }<0.7 \%\right)$. In the final section of this paper, the goodness of the CM approximation will be tested within the ICKA method in simulations of model TGA curves.

\subsection{Applicability of the universal integral form of the kinetic model to common solid-} state kinetic models

Table 1 summarizes the most common conversion functions used for the kinetic analysis of solid-state reactions. In the course of finding data for the table, we came across several mistakes that seem to have gone undetected from paper to paper: (i) wrong expressions for 
chemical $\left(\mathrm{F}_{n}\right)$ or diffusion mechanisms [37,38], (ii) analytical solutions of $g(\alpha)$ for kinetic models in which the solution of $g(\alpha)$ takes actually an infinite value [e.g., $g(\alpha)=$ $\ln [\alpha /(1-\alpha)][4,37,39]$ for the Prout-Tompkins $\left(\mathrm{B}_{1}\right)$ model $[40]$ or $g(\alpha)=\ln (\alpha)[4,37,39]$ for the exponential law $\left.\left(\mathrm{E}_{1}\right)\right]$. In Table 1 we attempted to circumvent these issues with an exhaustive review. The kinetic models were classified according to the trend of $f(\alpha)$ with $\alpha$ (decreasing, increasing or reaching a maximum), and subcategorized by the rate-determining step. Examples of the latter include phase boundary control, control by the product layer diffusion, control by the chemical reaction, nucleation control and grain growth control. The random pore model [41], random scission of polymer chain [42] and some empirical equations (non-justified mechanisms) [37] were also added to Table 1.

To determine the applicability of the ICKA method to the different kinetic models listed in Table 1, equations (9) or (12) were fitted to the data points obtained with the different $g(\alpha)$ functions listed in Table 1 , for 99 conversion values $\left(\alpha_{i}\right)$ from $\alpha_{1}=0.01$ to $\alpha_{99}=0.99$ (conversion step $=0.01$ ). The $Z, a, b$ and $c$ parameters where obtained via error minimization with the Solver complement of Microsoft ${ }^{\circledR}$ Office Excel, by using a mean squared error defined as:

$\left\langle\varepsilon_{s}(\alpha)\right\rangle=\frac{1}{99} \sum_{i=1}^{99}\left\{\ln \left[g\left(\alpha_{i}\right)\right]-\ln \left[g\left(\alpha_{i}\right)_{c a l}\right]\right\}^{2}$

where $g\left(\alpha_{i}\right)$ is evaluated at $\alpha=\alpha_{i}$ for a given kinetic mechanism and $g\left(\alpha_{i}\right)_{\text {cal }}$ is the corresponding value evaluated from equations (9) or (12). The use of logarithms in equation (19) permits to account for the occasional huge variation of $g\left(\alpha_{i}\right)$ values, which may spread over several orders of magnitude. To better interpret the errors, Table 1 shows the mean relative error $(\%)$ evaluated as: 
$\left\langle\varepsilon_{r}(\alpha)\right\rangle=\frac{100}{99} \sum_{i=1}^{99} \frac{g\left(\alpha_{i}\right)-g\left(\alpha_{i}\right)_{c a l}}{g\left(\alpha_{i}\right)_{c a l}}$

In the case of the random scission of polymer chain model for $L>2$ [42], the $f\left(\alpha_{i}\right)$ values were used instead of the $g\left(\alpha_{i}\right)$ values in equations (19) and (20), since the inverse of the conversion function ascribed to this kinetic model cannot be analytically integrated. Of course, the same change was necessarily made for the exponential law $\left(\mathrm{E}_{1}\right)$ and ProutTompkins $\left(\mathrm{B}_{1}\right)$ models $[g(\alpha)=\infty]$. The $Z, a, b$ and $c$ parameters obtained for all models are shown in Table 1.

Many of the kinetic models listed in Table 1 could be exactly reproduced by either equation (9) $\left[\mathrm{R}_{n}, \mathrm{D}_{1}, \mathrm{D}_{3}, \mathrm{~F}_{n}(n \neq 1), \mathrm{P}_{1 / n}, \mathrm{G}_{n}\right.$ and $\left.\mathrm{G}_{n}{ }_{n}\right]$ or equation (12) [ $\mathrm{F}_{n}(n=1), \mathrm{RPM}(\psi=0), \mathrm{G}_{n}{ }_{n}(n=3)$, $\mathrm{A}_{n}(n=1)$ and $\left.\mathrm{L}_{n}(n=2)\right]$. For the non-applicable models $\left(\mathrm{E}_{1}\right.$ and $\mathrm{B}_{1}$ in Table 1$)$ the fitting procedure was performed with the $f(\alpha)$ expression for $a \neq 0, b \neq 0$ and $c=0[g(\alpha)=\infty]$ shown in Table 2. This yielded an exact solution for the $E_{1}$ model (Table 1). Worthy of special mention is the attainment of a zero-error general solution for the $\mathrm{G}_{n}{ }_{n}$ model and a general solution for the Avrami-Erofe'ev nucleation model $\left(\mathrm{A}_{n}\right)$ with very low errors at any $n$ value (Table 1). Only some models produced non-zero errors (or, more precisely, non-zero standard deviations of the error). However, this error does not imply a significant nonconformity with the theoretical values. For the models with non-zero errors (some of the diffusion controlled models, the nucleation model, the random pore model, the random scission of polymer chain model and Prout-Tompkins model), Figures 3 to 5 show the comparison between the $f(\alpha)$ and $g(\alpha)$ values evaluated both from the theoretical kinetic model expressions for such functions and from the $Z, a, b$ and $c$ parameters shown in Table 1 . As can be seen in the figures, the agreement between both sets of curves is in general more than notable, especially in the case of $g(\alpha)$, which is the relevant function for the ICKA method. In view of these 
results, it can be concluded that equation (9) [and its limiting case, equation (12)] is of general application for the ICKA method.

\subsection{Validation of the ICKA method}

It is common today to claim that the validation of kinetic analysis methods requires their application to experimental TG (integral methods) or DTG (differential methods) curves. However, this procedure only yields examples of application rather than a true validation. All kinetic analysis methods for single solid state reactions assume Arrhenius-type behavior [equation (2)] and, in this sense, all of them are equivalent. Their differences are to be found in (i) the ease of application, (ii) the accuracy of the mathematical approximations, (iii) the application to TG (lower error) or DTG (higher error) data and (iv) the possibility of determining the conversion function or not. If a set of experimental data does not follow the Arrhenius-type behavior, then no kinetic analysis model will be applicable [43]. Conversely, an ideal set of experimental data that follows strictly the Arrhenius-type behavior and whose parameters are only too well known, would allow the validity of the different kinetic analysis models to be qualified according to the above mentioned criteria, but only at the conditions of the experimental reaction system. Furthermore, as the well-known kinetic parameters of this ideal system were derived with a previous kinetic analysis method, then we must ask ourselves how this previous method was validated at source. It is a vicious circle in which, at the end, we are validating the new method against old methods and not against experimental data. Thus, as Muravyev et al. [44] have already pointed, the only way to validate a kinetic analysis method is to use simulated kinetic curves in a wide range of kinetic conditions, following strictly the Arrhenius-type behavior, that have been built with a mathematical approach different from that of the kinetic analysis method itself. In this work, to validate the ICKA method simulated, $\alpha v s$. T curves were built for different kinetic models, that is to say, 
different conversion functions. The forward difference approximation was used to derive $\alpha$ from equation (2), by using extremely low time increments. Different $E, A_{0}$ and $s$ values were tested for three different heating rates $\left(3,5\right.$ and $\left.10^{\circ} \mathrm{C} \min ^{-1}\right)$. Equation (10) was fitted to 99 $\left(\alpha_{h r, i}, T\right)$ data pairs interpolated from the simulated curves at each of the three heating rates ( $h r$ subscript), from $\alpha_{h r, 1}=0.01$ to $\alpha_{h r, 99}=0.99$ (conversion step $=0.01$ ) amounting to 297 $\left(\alpha_{h r, i}, T\right)$ data pairs. The optimal values for $\ln \left(Z A_{0}\right), E, 1 / a, 1 / b$ and $1 / c$ were obtained by minimizing the mean squared error defined as:

$\left\langle\varepsilon^{\prime}{ }_{s}(\alpha)\right\rangle=\frac{1}{297} \sum_{h r=1}^{3} \sum_{i=1}^{99}\left[\alpha_{h r, i}-\left(\alpha_{h r, i}\right)_{c a l}\right]^{2}$

where $\alpha_{h r, i}$ represent a conversion value for a given kinetic mechanism and $\left(\alpha_{h r, i}\right)_{c a l}$ is the corresponding conversion value evaluated from equation (10). The parameters so obtained are indicated in Table 3, together with the average activation energy values determined by three standard integral methods; KAS (Kissinger, Akahira and Sunose [11,12]), FWO (Flynn, Wall and Ozawa $[9,10])$ and C-R (Coats and Redfern [13]). To better interpret the errors, Table 3 shows the mean relative error $(\%)$ of the ICKA method evaluated as:

$\left\langle\varepsilon^{\prime}{ }_{r}(\alpha)\right\rangle=\frac{100}{297} \sum_{h r=1}^{3} \sum_{i=1}^{99} \frac{\alpha_{h r, i}-\left(\alpha_{h r, i}\right)_{c a l}}{\alpha_{h r, i}}$

The kinetic models and parameters of the simulated curves were not selected for having any physical relevance or consistency but rather for covering representative ranges of $x$ values and a diversity of conversion functions. Thus, the following models and $x$ ranges were selected: $\mathrm{R}_{3}$ [example of decreasing $f(\alpha)$ ], $\mathrm{G}_{2}$ [example of increasing $f(\alpha)$ ], RPM ( $\psi=3$ ) [example of $f(\alpha)$ reaching a maximum], $4<x<9$ (for $\mathrm{G}_{2}$ ), $17<x<22$ (for $\mathrm{R}_{3}$ ) and $38<x<46$ (for RPM, $\psi=3)$. 
A distinction should be made between input and target parameters. Input parameters are those needed to build the simulated curves ( $E, A_{0}, s$ and the theoretical conversion function) whereas target parameters are $E$ and the $Z A_{0}, a, b$ and $c$ parameters that best match the theoretical conversion functions (Table 1). The results of applying the ICKA method to the simulated curves are shown in Table 3 and in Figures 6 to 8.

The effect of the selected time increment for building the simulation curves can be appreciated in the first two simulations of Figure 6 for the $\mathrm{R}_{3}$ model at $s=0$ (values indicated in Table 3). As can be observed, on decreasing the time increment from 0.25 to $0.13 \mathrm{~s}$, the already low error of the ICKA method further decreases and the resulting value for the activation energy is even more similar to the target value (shadowed cells in Table 3 ). This must be attributed to a better constructed simulation curve. In general, all the kinetic parameters obtained for the different models and $x$ ranges agree very nicely with the target values (Table 3) and, in all cases, the ICKA method provides better results than the KAS, FWO and C-R methods, since these were devised assuming $s=0$. These model-free methods obviously generate higher errors for $s \neq 0$. Not very significant deviations from the target parameters were occasionally encountered $\left(\mathrm{G}_{2}\right.$ for $s=-1.5$, and RPM for $\left.s=0\right)$, although this did not entail any relevant difference between the simulated and the calculated curves (Figs. 7 and 8), the former built with the original $f(\alpha)$ functions (Table 1) and not with the target $a, b, c$ and $Z$ values. It should be also noted that the Solver tool was run only once for each curve fitting; successive runs may improve the results. In conclusion, both the data shown in Table 3 and the excellent curve fittings observed in Figs. 6 to 8 indicate that the ICKA method is working properly and could turn into a valuable tool for studying the kinetics of solid-state reactions.

\section{Conclusions}


The ICKA method presented in this work accurately determines the activation energy and the kinetic model of single-step solid-state reaction processes. Two main factors contribute to the success of the method: (1) the general temperature integral has been approximated by means of a new rational expression that yields conspicuously better results than the previous approximations, and (2) a general integral form of the kinetic model of the type $g(\alpha)=$ $(a b c Z)^{-1}\left[1-\left(1-\alpha^{a}\right)^{b}\right]^{c}$ has been used to reproduce any known kinetic model, in most cases in an exact manner. The combination of these mathematical advances results in an equation for the conversion that has been successfully fitted to simulated conversion values of single-step reaction processes following different kinetic models. The error minimization yields the same values for the kinetic and conversion function parameters as those from which the simulated conversion curves were originally built.

\section{Acknowledgements}

The financial support for this research work provided by the FEDER Funds (GRUPIN2018IDI/2018/000148, Principado de Asturias) is gratefully acknowledged.

\section{References}

[1] J. Šesták, G. Berggren, Study of the kinetics of the mechanism of solid-state reactions at increasing temperatures, Thermochim Acta. 3 (1971) 1-12. https://doi.org/10.1016/0040-6031(71)85051-7.

[2] S. Vyazovkin, Modern isoconversional kinetics, in: The Handbook of Thermal Analysis and Calorimetry., Elsevier, 2018: pp. 131-172.

[3] S. Vyazovkin, A.K. Burnham, J.M. Criado, L.A. Pérez-Maqueda, C. Popescu, N. Sbirrazzuoli, ICTAC Kinetics Committee recommendations for performing kinetic computations on thermal analysis data, Thermochim. Acta. 520 (2011) 1-19. https://doi.org/10.1016/j.tca.2011.03.034. 
[4] L. Vlaev, V. Georgieva, M. Tavlieva, On the kinetic mechanism of non-isothermal degradation of solids, in: Reactions and Mechanisms in Thermal Analysis of Advanced Materials, Atul Tiwari Baldev Raj, 2015: pp. 547-575.

[5] R.R.A. Abou-Shaaban, A.P. Simonelli, Thermal analysis of reactions and transformations in the solid state. I. Experimental evaluation of published kinetic methods using thermogravimetry, Thermochim. Acta. 26 (1978) 67-88. https://doi.org/10.1016/0040-6031(78)80058-6.

[6] H.L. Friedman, Kinetics of Thermal Degradation of Char-Forming Plastics from Thermogravimetry. Application to a Phenolic Plastic, J. Polym. Sci. Part C. Polym. Symp. N 6 (1965) 183-195.

[7] L.A. Pérez-Maqueda, J.M. Criado, P.E. Sánchez-Jiménez, Combined kinetic analysis of solid-state reactions: A powerful tool for the simultaneous determination of kinetic parameters and the kinetic model without previous assumptions on the reaction mechanism, J Phys Chem A. 110 (2006) 12456-12462. https://doi.org/10.1021/jp064792g.

[8] J.B. Dahiya, K. Kumar, M. Muller-Hagedorn, H. Bockhorn, Kinetics of isothermal and non-isothermal degradation of cellulose: model-based and model-free methods, Polym. Int. 57 (2008) 722-729. https://doi.org/10.1002/pi.2398.

[9] J.H. Flynn, L.A. Wall, A quick direct method for the determination of activation energy from thermogravimetric data, J. Polym. Sci. Part B. Polymer Letters Banner. (1966) 323-328.

[10] Ozawa Takeo, A new method of analyzing thermogravimetric data, Bulletin of the Chemical Society Japan. 38 (1965) 1881-1886.

[11] H.E. Kissinger, Reaction Kinetics in Differential Thermal Analysis, Anal. Chem. 29 (1957) 1702-1706.

[12] T. Akahira., T. Sunose., Method of determining activation deterioration constant of electrical insulating materials., Res. Rep. Chiba Inst. Technol. 16 (1971) 22-31.

[13] A.W. Coats, J.P. Redfern, Kinetic parameters from thermogravimetric data, Nature. 201 (1964) 68-69. https://doi.org/10.1038/201068a0.

[14] J.M. Criado, L.A. Pérez-Maqueda, P.E. Sánchez-Jiménez, Dependence of the preexponential factor on temperature: Errors in the activation energies calculated by assuming that A is constant, J. Therm. Anal. Calor. 82 (2005) 671-675. https://doi.org/10.1007/s10973-005-0948-3.

[15] J.M. Cai, R.H. Liu, New approximation for the general temperature integral, J. Therm. Anal. Calor. 90 (2007) 469-474. https://doi.org/10.1007/s10973-006-8178-x.

[16] V.M. Gorbachev, A solution of the exponential integral in the non-isothermal kinetics for linear heating, J. Thermal Anal. 8 (1975) 349-350. https://doi.org/10.1007/BF01904012.

[17] T. Wanjun, L. Yuwen, Y. Xil, W. Zhiyong, W. Cunxin, Approximate formulae for calculation of the integral $\int \mathrm{T}^{\wedge} \mathrm{m} \exp (-\mathrm{E} / \mathrm{RT}) \mathrm{dT}$, J. Therm. Anal. Calor. 81 (2005) 347349. https://doi.org/10.1007/s10973-005-0790-7.

[18] J.M. Cai, D. Han, Empirical formula for temperature integral in non-isothermal kinetics for exponential heating, J. Energy Inst. 83 (2010) 75-78. https://doi.org/10.1179/014426010X12682307291308.

[19] J. Han, D. Liu, L. Qin, W. Chen, F. Xing, A modified temperature integral approximation formula and its application in pyrolysis kinetic parameters of waste tire, Energy Sources Recovery Util. Environ. Eff. 40 (2018) 220-226. https://doi.org/10.1080/15567036.2017.1410596. 
[20] W. Tang, Y. Liu, H. Zhang, C. Wang, New approximate formula for Arrhenius temperature integral, Thermochim Acta. 408 (2003) 39-43. https://doi.org/10.1016/S0040-6031(03)00310-1.

[21] L.A. Pérez-Maqueda, P.E. Sánchez-Jiménez, J.M. Criado, Kinetic analysis of solid-state reactions: Precision of the activation energy calculated by integral methods, Int. J. Chem. Kinet. 37 (2005) 658-666. https://doi.org/10.1002/kin.20115.

[22] A. Khawam, D.R. Flanagan, Solid-state kinetic models: Basics and mathematical fundamentals, J Phys Chem B. 110 (2006) 17315-17328. https://doi.org/10.1021/jp062746a.

[23] H. Tanaka, Thermal analysis and kinetics of solid state reactions, Thermochim. Acta. 267 (1995) 29-44. https://doi.org/10.1016/0040-6031(95)02464-6.

[24] P.E. Sánchez-Jiménez, L.A. Pérez-Maqueda, A. Perejón, J.M. Criado, Generalized master plots as a straightforward approach for determining the kinetic model: The case of cellulose pyrolysis, Thermochim. Acta. 552 (2013) 54-59. https://doi.org/10.1016/j.tca.2012.11.003.

[25] L.A. Pérez-Maqueda, J.M. Criado, F.J. Gotor, J. Málek, Advantages of combined kinetic analysis of experimental data obtained under any heating profile, J. Phys. Chem. A. 106 (2002) 2862-2868. https://doi.org/10.1021/jp012246b.

[26] J. Cai, R. Liu, Kinetic analysis of solid-state reactions: A general empirical kinetic model, Ind. Eng. Chem. Res. 48 (2009) 3249-3253. https://doi.org/10.1021/ie8018615.

[27] D.M. Bates, D.G. Watts, Nonlinear regression analysis and its applications, Wiley New York, 1988.

[28] M.J. Starink, The determination of activation energy from linear heating rate experiments: A comparison of the accuracy of isoconversion methods, Thermochim Acta. 404 (2003) 163-176. https://doi.org/10.1016/S0040-6031(03)00144-8.

[29] S.A. Epshtein, E.L. Kossovich, V.A. Kaminskii, N.M. Durov, N.N. Dobryakova, Solid fossil fuels thermal decomposition features in air and argon, Fuel. 199 (2017) 145-156. https://doi.org/10.1016/j.fuel.2017.02.084.

[30] M. Radojević, B. Janković, V. Jovanović, D. Stojiljković, N. Manić, Comparative pyrolysis kinetics of various biomasses based on model-free and DAEM approaches improved with numerical optimization procedure, PLOS ONE. 13 (2018). https://doi.org/10.1371/journal.pone.0206657.

[31] R. Tuffi, S. D’Abramo, L.M. Cafiero, E. Trinca, S. Vecchio Ciprioti, Thermal behavior and pyrolytic degradation kinetics of polymeric mixtures from waste packaging plastics, Express Polym. Lett. 12 (2018) 82-99. https://doi.org/10.3144/expresspolymlett.2018.7.

[32] L. Liqing, C. Donghua, Application of ISO-temperature method of multiple rate to kinetic analysis: Dehydration for calcium oxalate monohydrate, J. Therm. Anal. Calor. 78 (2004) 283-293. https://doi.org/10.1023/B:JTAN.0000042175.27569.ee.

[33] C. Deng, J. Cai, R. Liu, Kinetic analysis of solid-state reactions: Evaluation of approximations to temperature integral and their applications, Solid State Sci. 11 (2009) 1375-1379. https://doi.org/10.1016/j.solidstatesciences.2009.04.009.

[34] G.I. Senum, R.T. Yang, Rational approximations of the integral of the Arrhenius function, J. Thermal Anal. 11 (1977) 445-447. https://doi.org/10.1007/BF01903696.

[35] Y. Lin, Y. Tian, Y. Xia, S. Fang, Y. Liao, Z. Yu, X. Ma, General distributed activation energy model (G-DAEM) on co-pyrolysis kinetics of bagasse and sewage sludge, Bioresour. Technol. (2019) 545-555. https://doi.org/10.1016/j.biortech.2018.11.051.

[36] C.D. Doyle, Estimating isothermal life from thermogravimetric data, J. Appl. Polym. Sci. 6 (1962) 639-642. https://doi.org/10.1002/app.1962.070062406. 
[37] L. Vlaev, N. Nedelchev, K. Gyurova, M. Zagorcheva, A comparative study of nonisothermal kinetics of decomposition of calcium oxalate monohydrate, J Anal Appl Pyrolysis. 81 (2008) 253-262. https://doi.org/10.1016/j.jaap.2007.12.003.

[38] P. Ptáček, F. Šoukal, T. Opravil, E. Bartoníčková, J. Wasserbauer, The formation of feldspar strontian (SrA12Si2O8) via ceramic route: Reaction mechanism, kinetics and thermodynamics of the process, Ceramics International. 42 (2016) 8170-8178. https://doi.org/10.1016/j.ceramint.2016.02.024.

[39] P. Budrugeac, E. Segal, Some methodological problems concerning nonisothermal kinetic analysis of heterogeneous solid-gas reactions, J. Chem. Kinet. 33 (2001) 564 573. https://doi.org/10.1002/kin.1052.

[40] E.G. Prout, F.C. Tompkins, The thermal decomposition of potassium permanganate, Transactions of the Faraday Society. 40 (1944) 488-498. https://doi.org/10.1039/tf9444000488.

[41] S.K. Bhatia, D.D. Perlmutter, A random pore model for fluid-solid reactions: I. Isothermal, kinetic control, AIChE Journal. 26 (1980) 379-386. https://doi.org/10.1002/aic.690260308.

[42] P.E. Sánchez-Jiménez, L.A. Pérez-Maqueda, A. Perejón, J.M. Criado, A new model for the kinetic analysis of thermal degradation of polymers driven by random scission, Polym. Degrad. Stabil. 95 (2010) 733-739. https://doi.org/10.1016/j.polymdegradstab.2010.02.017.

[43] P.J. Skrdla, Can we trust kinetic methods of thermal analysis?, Analyst. 145 (2020) 745749. https://doi.org/10.1039/c9an01477b.

[44] N.V. Muravyev, A.N. Pivkina, N. Koga, Critical appraisal of kinetic calculation methods applied to overlapping multistep reactions, Molecules. 24 (2019). https://doi.org/10.3390/molecules24122298.

[45] J.T. Carstensen, Stability of solids and solid dosage forms, J. Pharm. Sci. 63 (1974) 114. https://doi.org/10.1002/jps.2600630103.

[46] G. Valensi, Analysis of the methods of interpreting reactions of a gas with a solid to form another solid, J. Phys. Chem. Biol. 47 (1950) 489-505.

[47] W. Jander, Z. Anorg, Kinetic Model for Solid-State Reactions., Angew. Chem. 163 (1927) 1-30.

[48] A.M. Ginstling, B.I. Brounshtein, On diffusion kinetics in chemical reactions taking place in spherical powder grains, Zh. Prikl. Khim. 23 (1950) 1327.

[49] V.F. Zuravlev, I.G. Lesokhin, R.G. Tempel'man, Kinetics of the formation of aluminates and the role of mineralizers in this process, J. Appl. Chem. USSR. 21 (1948) 887.

[50] W. Komatsu, T. Uemura, Kinetic equations of solid state reactions for counterdiffusion systems, Zeitschrift Fur Physikalische Chemie. 72 (1970) 59-75. https://doi.org/10.1524/zpch.1970.72.1_3.059.

[51] I.F. Kononiuk, Geterogennie Khimitceskie Reaktzii i Reaktzionnaia Sposobnostip. 93, Nauka i Tekhnika, Minsk. (1945) 53.

[52] K.N. Ninan, K. Krishnan, V.N. Krishnamurthy, Kinetics and mechanism of thermal decomposition of insitu generated calcium carbonate, J. Thermal Anal. 37 (1991) 15331543. https://doi.org/10.1007/BF01913486.

[53] M. Avrami, Granulation, phase change, and microstructure kinetics of phase change. III, J. Chem. Phys. 9 (1941) 177-184. https://doi.org/10.1063/1.1750872.

[54] M. Avrami, Kinetics of phase change. II Transformation-time relations for random distribution of nuclei, J. Chem. Phys. 8 (1940) 212-224. https://doi.org/10.1063/1.1750631. 
[55] M. Avrami, Kinetics of phase change. I: General theory, J. Chem. Phys. 7 (1939) $1103-$ 1112. https://doi.org/10.1063/1.1750380.

[56] B.V. Erofe'ev, C.R. Dokl, A generalized equation of chemical kinetics and ist application in reactions involving solids, Acad. Sci. URSS. 52 (1946) 511.

[57] K.L. Mampel, Time conversion formulas for heterogeneous reactions at the phase boundaries of solid bodies, I: The development of the mathematical method and the derivation of area conversion formulas, Z. Phys. Chem. Abt. A 187 (1940) 235. 
Tables 
Table 1. Algebraic expressions of $f(\alpha)$ and $g(\alpha)$ functions for the most common kinetic models

\begin{tabular}{|c|c|c|c|c|c|c|c|c|}
\hline Model (equation) * & $f(\alpha)$ & $g(\alpha)$ & Range & $\boldsymbol{Z}$ & $\bar{a}$ & b & $c$ & $\left\langle\varepsilon_{r}(\alpha)\right\rangle(\%)$ \\
\hline \multicolumn{9}{|l|}{ 1. Decreasing $f(\alpha)$} \\
\hline \multicolumn{9}{|c|}{ 1.1. Phase boundary controlled reaction (for $n<1, f(\alpha)$ becomes an increasing function) } \\
\hline \multirow{4}{*}{$\mathrm{R}_{n}$ (Power law) $[22,45]$} & 1 & $\alpha$ & $n=1$ & 1 & 1 & 1 & 1 & $0.00 \pm 0.00$ \\
\hline & $2(1-\alpha)^{1 / 2}$ & $1-(1-\alpha)^{1 / 2}$ & $n=2$ & 2 & 1 & $1 / 2$ & 1 & $0.00 \pm 0.00$ \\
\hline & $3(1-\alpha)^{2 / 3}$ & $1-(1-\alpha)^{1 / 3}$ & $n=3$ & 3 & 1 & $1 / 3$ & 1 & $0.00 \pm 0.00$ \\
\hline & $n(1-\alpha)^{1-1 / n}$ & $1-(1-\alpha)^{1 / n}$ & $n>0$ & $n$ & 1 & $1 / n$ & 1 & $0.00 \pm 0.00$ \\
\hline \multicolumn{9}{|l|}{ 1.2. Diffusion mechanisms } \\
\hline $\mathrm{D}_{1}$ (Parabolic law) [37] & {$[1 /(2 \alpha)]$} & $\alpha^{2}$ & & 0.5 & 1 & 1 & 2 & $0.00 \pm 0.00$ \\
\hline $\mathrm{D}_{3}$ (Jander) [47] & {$\left[3(1-\alpha)^{2 / 3}\right] /\left\{2\left[1-(1-\alpha)^{1 / 3}\right]\right\}$} & {$\left[1-(1-\alpha)^{1 / 3}\right]^{2}$} & & 1.5 & 1 & $1 / 3$ & 2 & $0.00 \pm 0.00$ \\
\hline $\begin{array}{l}\mathrm{D}_{4} \text { (Ginstling Brounshtein) } \\
\text { [48] }\end{array}$ & $3 /\left\{2\left[(1-\alpha)^{-1 / 3}-1\right]\right\}$ & {$[1-(2 \alpha / 3)]-(1-\alpha)^{2 / 3}$} & & 2.51015700 & 0.93484493 & 0.58763787 & 2.13503186 & $0.00 \pm 0.08$ \\
\hline $\begin{array}{l}\mathrm{D}_{5} \text { (Zhuravlev, Lesokin, } \\
\text { Tempelman) [49] }\end{array}$ & {$\left[3(1-\alpha)^{4 / 3}\right] /\left\{2\left[(1-\alpha)^{-1 / 3}-1\right]\right\}$} & {$\left[(1-\alpha)^{-1 / 3}-1\right]^{2}$} & & $5.7796938 \times 10^{-15}$ & 0.52837508 & $2.3145783 \times 10^{-7}$ & 3.32086055 & $-0.19 \pm 6.11$ \\
\hline $\mathrm{D}_{6}$ (Anti-Jander) [50] & {$\left[3(1+\alpha)^{2 / 3}\right] /\left\{2\left[(1+\alpha)^{1 / 3}-1\right]\right\}$} & {$\left[(1+\alpha)^{1 / 3}-1\right]^{2}$} & & 3.51309687 & $4.0564594 \times 10^{-6}$ & 1.06924201 & $9.9088559 \times 10^{5}$ & $0.00 \pm 0.48$ \\
\hline $\begin{array}{l}\mathrm{D}_{7} \text { (Anti-Ginstling } \\
\text { Brounshtein) [51] }\end{array}$ & $3 /\left\{2\left[1-(1+\alpha)^{-1 / 3}\right]\right\}$ & {$[1+(2 \alpha / 3)]-(1+\alpha)^{2 / 3}$} & & 3.28862175 & $1.3304076 \times 10^{-7}$ & 1.04603061 & $2.7965113 \times 10^{7}$ & $0.00 \pm 0.34$ \\
\hline \multicolumn{9}{|l|}{ 1.3. Chemical reaction } \\
\hline $\mathrm{F}_{n}[52]$ & $(1-\alpha)^{n}$ & $-\ln (1-\alpha)$ & $n=1$ & 1 & 1 & 0 & 1 & $0.00 \pm 0.00$ \\
\hline & & {$\left[(1-\alpha)^{1-n}-1\right] /(n-1)$} & $n \neq 1$ & 1 & 1 & $1-n$ & 1 & $0.00 \pm 0.00$ \\
\hline \multicolumn{9}{|c|}{ 1.4. Random pore model $[f(\alpha)$ decreases with $\alpha$ for $\psi \leq 2$ ( $\psi=$ structural parameter $)]$} \\
\hline \multirow{3}{*}{ RPM (Bhatia-Perlmutter) [41] } & \multirow{3}{*}{$(1-\alpha)[1-\psi \ln (1-\alpha)]^{1 / 2}$} & $-\ln (1-\alpha)$ & $\psi=0$ & 1 & 1 & 0 & 1 & $0.00 \pm 0.00$ \\
\hline & & \multirow{2}{*}{$(2 / \psi)\left\{[1-\psi \ln (1-\alpha)]^{1 / 2}-1\right\}$} & $\psi=1$ & $1.7644881 \times 10^{3}$ & 1.50901576 & $1 \times 10^{-10}$ & 0.67235556 & $0.00 \pm 0.35$ \\
\hline & & & $\psi=2$ & $2.1407838 \times 10^{4}$ & 1.75405183 & $1 \times 10^{-10}$ & 0.56770866 & $0.00 \pm 0.19$ \\
\hline $\begin{array}{l}\text { 1.5. Nucleation } \\
\mathrm{A}_{n} \text { (Avrami-Erofe'ev) [53-56] }\end{array}$ & $(1-\alpha)$ & {$[-\ln (1-\alpha)]$} & $n=1$ & 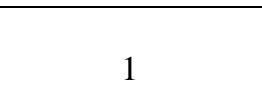 & 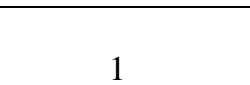 & 0 & 1 & $0.00 \pm 0.00$ \\
\hline \multicolumn{9}{|l|}{ 1.6. Non-justified mechanisms } \\
\hline $\mathrm{G}_{n}[37]$ & {$[1 /(n-2)](1-\alpha) /[-\ln (1-\alpha)]^{n-3}$} & {$[-\ln (1-\alpha)]^{n-2}$} & $n=3$ & 1 & 1 & 0 & 1 & $0.00 \pm 0.00$ \\
\hline$n\left[\begin{array}{ll}n \\
n\end{array}\right.$ & & & $n>3$ & {$\left[10^{-10(n-3)}\right] /(n-2)$} & 1 & $1 \times 10^{-10}$ & $n-2$ & $0.00 \pm 0.00$ \\
\hline \multicolumn{9}{|l|}{ 2. Increasing $f(\alpha)$} \\
\hline \multicolumn{9}{|l|}{ 2.1. Nucleation } \\
\hline $\mathrm{P}_{1 / n}$ (Mampel power law) [57] & $n \alpha^{1-1 / n}$ & $\alpha^{1 / n}$ & $n>0$ & $n$ & 1 & 1 & $1 / n$ & $0.00 \pm 0.00$ \\
\hline \multicolumn{9}{|l|}{ 2.2. Non-justified mechanisms } \\
\hline $\mathrm{G}_{n}[37]$ & $1 /\left[(n+1)(1-\alpha)^{n}\right]$ & $1-(1-\alpha)^{n+1}$ & $n \geq 1$ & $1 /(n+1)$ & 1 & $n+1$ & 1 & $0.00 \pm 0.00$ \\
\hline
\end{tabular}


Table 1. Algebraic expressions of $f(\alpha)$ and $g(\alpha)$ functions for the most common kinetic models (continuation)

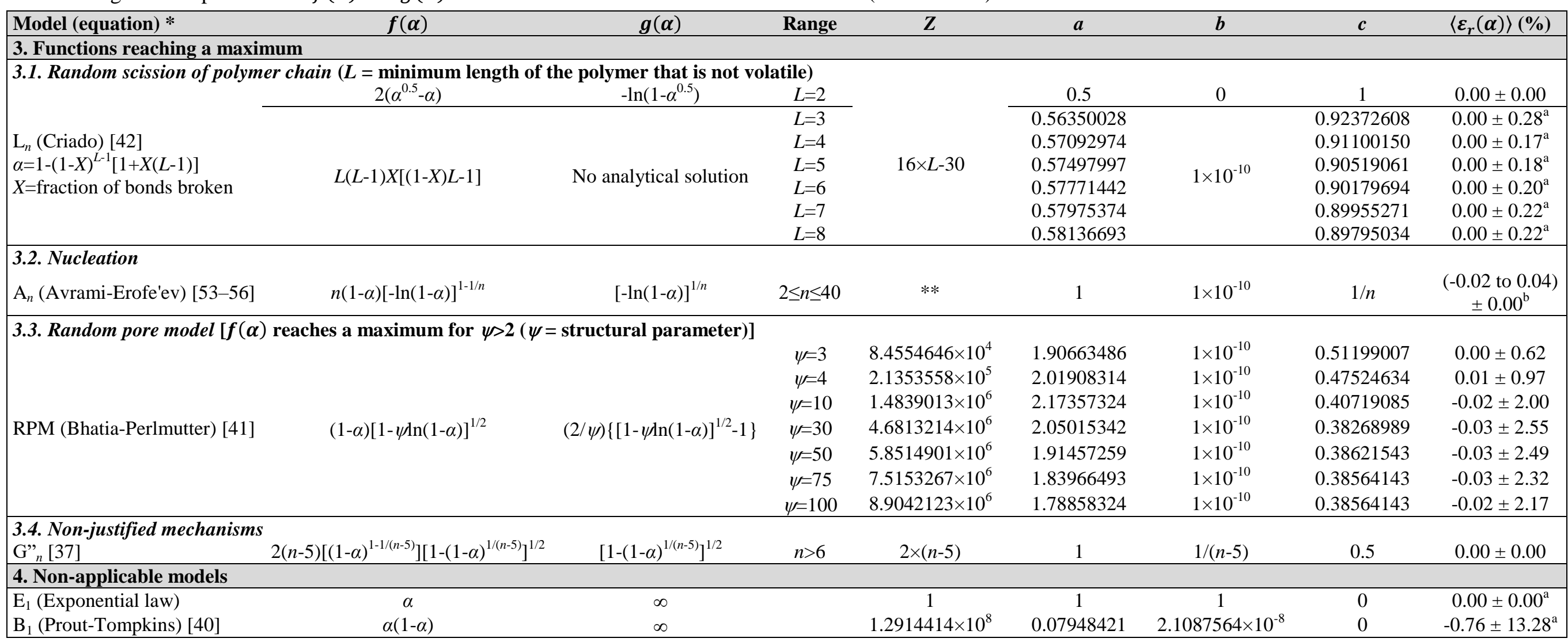

$* \mathrm{R}_{1}$ : Contracting disk (and some cases of evaporation); $\mathrm{R}_{2}$ : Contracting area-cylinder or prism; $\mathrm{R}_{3}$ : Contracting volume-sphere; $\mathrm{D}_{1}$ : One-dimensional diffusion; $\mathrm{D}_{2}$ : Two-dimensional diffusion; $\mathrm{D}_{3}-\mathrm{D}_{8}$ : Three-dimensional diffusion; $\mathrm{F}_{n}$ : Chemical reaction; $\mathrm{P}_{1 / n}$ : Nucleation; $\mathrm{A}_{n}$ : Random nucleation and growth of nuclei through different nucleation and nucleus growth models; $\mathrm{L}_{n}$ : Random scission of polymer chain;

$* * Z=\exp \left[v_{1}(n-1)^{v_{2}} n^{v_{3}}(n+1)^{v_{4}}\right]$, where $v_{1}=23.49386823, v_{2}=1.003023492, v_{3}=-1.006412928, v_{4}=0.038935143$;

${ }^{\text {a }}$ Relative error in $f(\alpha)$

${ }^{\mathrm{b}}$ Error range in brackets 
Table 2. Expressions for $f(\alpha)$ and $g(\alpha)$ at limiting cases

\begin{tabular}{|cccccc|}
\hline $\boldsymbol{A}$ & $\boldsymbol{b}$ & $\boldsymbol{c}$ & $\boldsymbol{f}(\boldsymbol{\alpha})$ & $\boldsymbol{g}(\boldsymbol{\alpha})$ & Method of solution \\
\hline 0 & $\neq 0$ & $\neq 0$ & 0 & $\infty$ & - \\
$\neq 0$ & $\neq 0$ & 0 & $Z\left[1-\left(1-\alpha^{a}\right)^{b}\right]\left(1-\alpha^{a}\right)^{1-b} \alpha^{1-a}$ & $\infty$ & - \\
$\neq 0$ & 0 & $>1$ & 0 & 0 & L'Hôpital \\
$\neq 0$ & 0 & $<1$ & 0 & Complex & L'Hôpital \\
$\neq 0$ & 0 & 1 & $Z\left(1-\alpha^{a}\right) \alpha^{1-a}$ & $-\left[\ln \left(1-\alpha^{a}\right)\right] /(a Z)$ & L'Hôpital \\
\hline
\end{tabular}


Table 3. Results of applying different integral methods to a variety of kinetic models (target $a, b, c$, $Z A_{0}$ and $E$ values in shadowed cells)

\begin{tabular}{|c|c|c|c|c|c|c|c|}
\hline Kinetic model & $s$ & $a$ & $b$ & $c$ & $\begin{array}{c}Z A_{0} \\
\left(\mathbf{s}^{-1} \mathbf{K}^{-s}\right)\end{array}$ & $\begin{array}{c}E \\
(\mathrm{~J} / \mathrm{mol}) \\
\end{array}$ & $\begin{array}{c}\left\langle\varepsilon^{\prime}{ }_{r}(\boldsymbol{\alpha})\right\rangle \\
\%\end{array}$ \\
\hline $\mathrm{R}_{3}(\Delta \mathrm{t}=0.25 \mathrm{~s})^{\mathrm{a}}$ & 0.0 & 1.000 & 0.333 & 1.000 & $6.00 \times 10^{7}$ & 100000 & \\
\hline ICKA & - & 0.999 & 0.334 & 1.001 & $5.95 \times 10^{7}$ & 99966 & $0.00 \pm 0.01$ \\
\hline KAS & - & - & - & - & - & $99657 \pm 12$ & - \\
\hline FWO & - & - & - & - & - & $102678 \pm 323$ & - \\
\hline C-R & - & - & - & - & - & $99733 \pm 2$ & - \\
\hline $\mathrm{R}_{3}(\Delta \mathrm{t}=0.13 \mathrm{~s})^{\mathrm{a}}$ & 0.0 & 1.000 & 0.333 & 1.000 & $6.00 \times 10^{7}$ & 100000 & \\
\hline ICKA & - & 0.999 & 0.334 & 1.001 & $5.97 \times 10^{7}$ & 99983 & $0.00 \pm 0.00$ \\
\hline KAS & - & - & - & - & - & $99677 \pm 13$ & - \\
\hline FWO & - & - & - & - & - & $102696 \pm 313$ & - \\
\hline C-R & - & - & - & - & - & $99723 \pm 6$ & - \\
\hline $\mathrm{R}_{3}(\Delta \mathrm{t}=0.25 \mathrm{~s})^{\mathrm{a}}$ & -1.5 & 1.000 & 0.333 & 1.000 & $6.00 \times 10^{9}$ & 100000 & \\
\hline ICKA & - & 0.999 & 0.334 & 1.000 & $5.98 \times 10^{9}$ & 99981 & $0.00 \pm 0.00$ \\
\hline KAS & - & - & - & - & - & $92102 \pm 405$ & - \\
\hline FWO & - & - & - & - & - & $97378 \pm 131$ & - \\
\hline $\mathrm{C}-\mathrm{R}$ & - & - & - & - & - & $92389 \pm 223$ & - \\
\hline $\mathrm{R}_{3}(\Delta \mathrm{t}=0.25 \mathrm{~s})^{\mathrm{a}}$ & +1.5 & 1.000 & 0.333 & 1.000 & 6.00 & 100000 & \\
\hline ICKA & - & 0.999 & 0.334 & 1.000 & 6.00 & 100001 & $0.00 \pm 0.00$ \\
\hline KAS & - & - & - & - & - & $107454 \pm 350$ & - \\
\hline FWO & - & - & - & - & - & $112688 \pm 849$ & - \\
\hline C-R & - & - & - & - & - & $107294 \pm 192$ & - \\
\hline $\mathrm{G}_{2}(\Delta \mathrm{t}=0.25 \mathrm{~s})^{\mathrm{b}}$ & 0.0 & 1.000 & 3.000 & 1.000 & $6.67 \times 10^{-2}$ & 25000 & \\
\hline ICKA & - & 0.999 & 2.997 & 1.000 & $6.62 \times 10^{-2}$ & 24974 & $0.04 \pm 0.20$ \\
\hline KAS & - & - & - & - & - & $23979 \pm 156$ & - \\
\hline FWO & - & - & - & - & - & $31488 \pm 522$ & - \\
\hline $\mathrm{C}-\mathrm{R}$ & - & - & - & - & - & $24179 \pm 142$ & - \\
\hline $\mathrm{G}_{2}(\Delta \mathrm{t}=0.25 \mathrm{~s})^{\mathrm{b}}$ & -1.5 & 1.000 & 3.000 & 1.000 & $5.83 \times 10^{2}$ & 25000 & \\
\hline ICKA & - & 0.953 & 2.805 & 0.967 & $6.77 \times 10^{2}$ & 24974 & $0.69 \pm 2.89$ \\
\hline KAS & - & - & - & - & - & $17608 \pm 767$ & - \\
\hline FWO & - & - & - & - & - & $25747 \pm 117$ & - \\
\hline $\mathrm{C}-\mathrm{R}$ & - & - & - & - & - & $18585 \pm 698$ & - \\
\hline $\mathrm{G}_{2}(\Delta \mathrm{t}=0.25 \mathrm{~s})^{\mathrm{b}}$ & +1.5 & 1.000 & 3.000 & 1.000 & $3.33 \times 10^{-6}$ & 25000 & \\
\hline ICKA & - & 0.996 & 2.992 & 1.002 & $3.26 \times 10^{-6}$ & 24895 & $-0.05 \pm 0.48$ \\
\hline KAS & - & - & - & - & - & $30599 \pm 318$ & - \\
\hline FWO & - & - & - & - & - & $38424 \pm 952$ & - \\
\hline $\mathrm{C}-\mathrm{R}$ & - & - & - & - & - & $30181 \pm 289$ & - \\
\hline $\operatorname{RPM}(\psi=3, \Delta \mathrm{t}=0.1 \mathrm{~s})^{\mathrm{c}}$ & 0.0 & 1.907 & $1 \times 10^{-10}$ & 0.512 & $8.46 \times 10^{19}$ & 200000 & \\
\hline ICKA & - & 1.856 & $9.993 \times 10^{-11}$ & 0.519 & $7.18 \times 10^{7}$ & 199921 & $0.06 \pm 0.54$ \\
\hline KAS & - & - & - & - & - & $199736 \pm 30$ & - \\
\hline FWO & - & - & - & - & - & $199267 \pm 221$ & - \\
\hline $\mathrm{C}-\mathrm{R}$ & - & - & - & - & - & $199824 \pm 4$ & - \\
\hline $\operatorname{RPM}(\psi=3, \Delta \mathrm{t}=0.1 \mathrm{~s})^{\mathrm{c}}$ & -1.5 & 1.907 & $1 \times 10^{-10}$ & 0.512 & $8.46 \times 10^{23}$ & 200000 & \\
\hline ICKA & - & 1.902 & $1.001 \times 10^{-10}$ & 0.511 & $8.66 \times 10^{23}$ & 199906 & $0.01 \pm 0.36$ \\
\hline KAS & - & - & - & - & - & $192424 \pm 180$ & - \\
\hline FWO & - & - & - & - & - & $192394 \pm 68$ & - \\
\hline $\mathrm{C}-\mathrm{R}$ & - & - & - & - & - & $192614 \pm 106$ & - \\
\hline $\operatorname{RPM}(\psi=3, \Delta \mathrm{t}=0.1 \mathrm{~s})^{\mathrm{c}}$ & +1.5 & 1.907 & $1 \times 10^{-10}$ & 0.512 & $8.46 \times 10^{15}$ & 200000 & \\
\hline ICKA & - & 1.902 & $9.999 \times 10^{-11}$ & 0.511 & $8.93 \times 10^{15}$ & 200094 & $0.02 \pm 0.36$ \\
\hline KAS & - & - & - & - & - & $206945 \pm 163$ & - \\
\hline FWO & - & - & - & - & - & $206047 \pm 363$ & - \\
\hline $\mathrm{C}-\mathrm{R}$ & - & - & - & - & - & $206939 \pm 95$ & - \\
\hline
\end{tabular}

${ }^{\mathrm{a}}$ Fig. $6 ;^{\mathrm{b}}$ Fig. 7 ; $^{\mathrm{c}}$ Fig. 8 


\section{Figures Legends}

Figure 1. Error values of CM approximation (solid circles) for different values of the $s$ parameter. Lines corresponding to previous approximations, only valid for $s=0$, have also been included $\{\mathrm{C}-\mathrm{R}$ (Coats-Redfern) [13], Doyle [36], Tang [20] and Han [19] approximations \}

Figure 2. Error comparison between CM and Lin_New approximations

Figure 3. Conversion functions, $f(\alpha)$, and integral forms of the kinetic models, $g(\alpha)$, evaluated both by the kinetic model equations ( $f(\alpha)$ : open triangles; $g(\alpha)$ : open circles) and by equations (8) and (9) (lines), for some diffusion controlled kinetic models

Figure 4. Conversion functions, $f(\alpha)$, and integral forms of the kinetic models, $g(\alpha)$, evaluated both by the kinetic model equations ( $f(\alpha)$ : open triangles; $g(\alpha)$ : open circles) and by equations (8) and (9) (lines), for the nucleation model ( $n=6$ and $n=20$ ), random pore model ( $\psi=1$ and $\psi=3$ ) and for the random scission of polymer chain model ( $L=4$ and $L=6$ )

Figure 5. Conversion function, $f(\alpha)$ evaluated both by the kinetic model equation (symbols) and by equation (8) (lines), for the Prout-Tompkins model

Figure 6. Results of applying the ICKA method to simulated conversion curves obtained for the $\mathrm{R}_{3}$ model with the kinetic parameters indicated in the figures themselves. Left plots: simulated (symbols) and calculated (lines) conversion values at the three heating rates analyzed; right plots: simulated (symbols) and calculated (lines) normalized conversion functions. Values of kinetic parameters in Table 3

Figure 7. Results of applying the ICKA method to simulated conversion curves obtained for the $\mathrm{G}_{2}$ model with the kinetic parameters indicated in the figures themselves. Left plots: simulated (symbols) and calculated (lines) conversion values at the three heating rates analyzed; right plots: simulated 
(symbols) and calculated (lines) normalized conversion functions. Values of kinetic parameters in Table 3

Figure 8. Results of applying the ICKA method to simulated conversion curves obtained for the RPM $(\psi=3)$ model with the kinetic parameters indicated in the figures themselves. Left plots: simulated (symbols) and calculated (lines) conversion values at the three heating rates analyzed; right plots: simulated (symbols) and calculated (lines) normalized conversion functions. Values of kinetic parameters in Table 3 
Figures

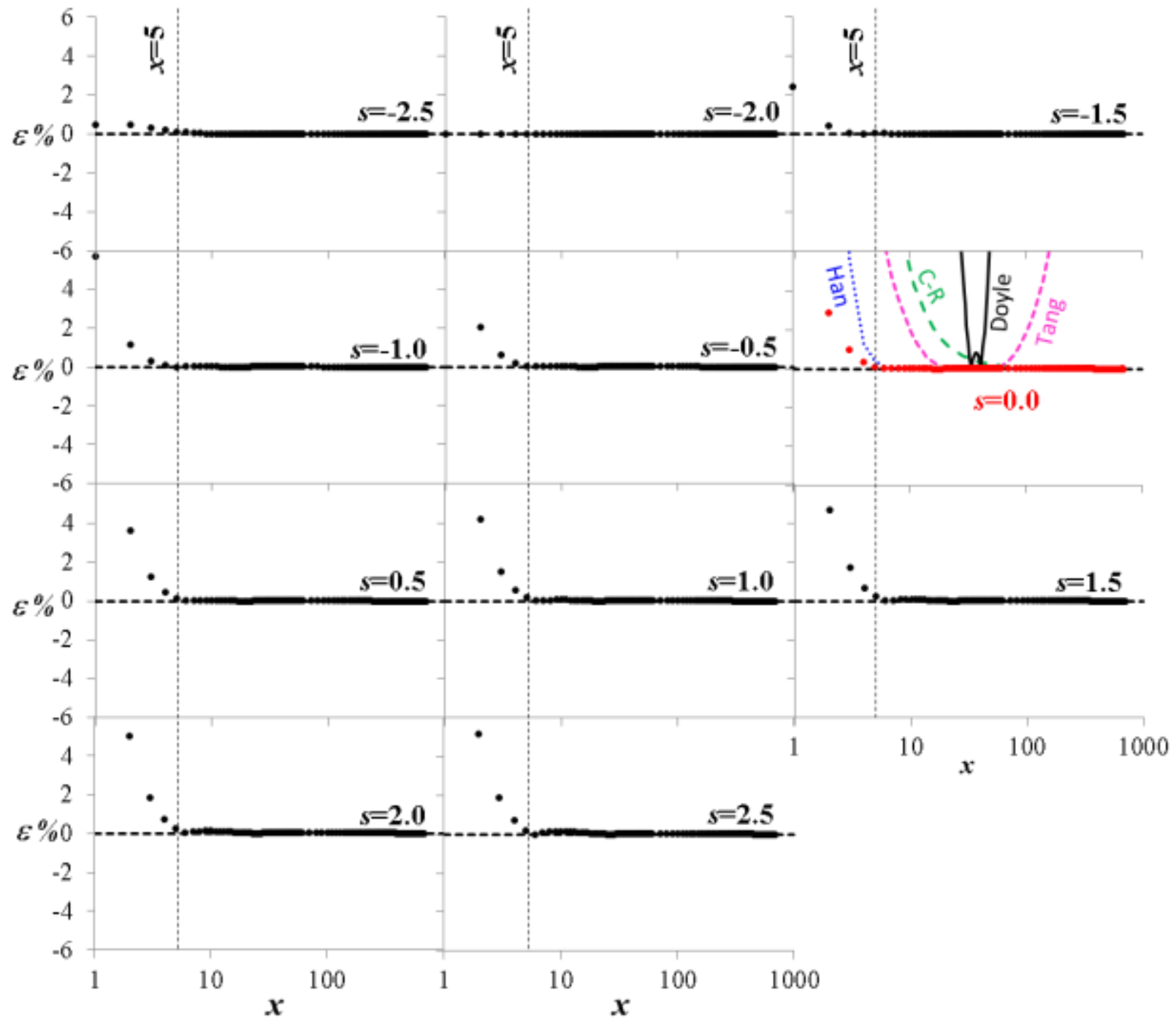

Figure 1 


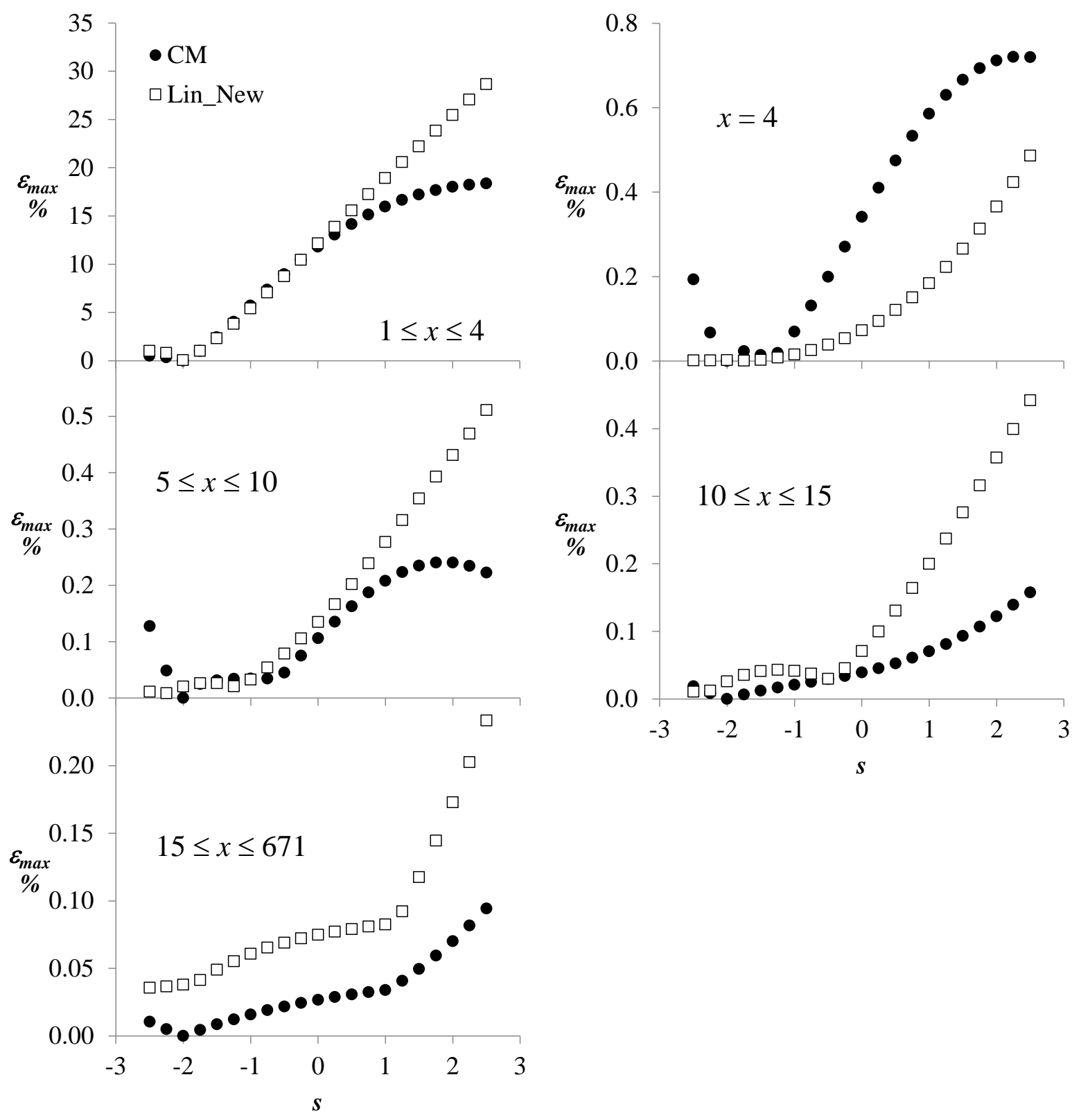

Figure 2 


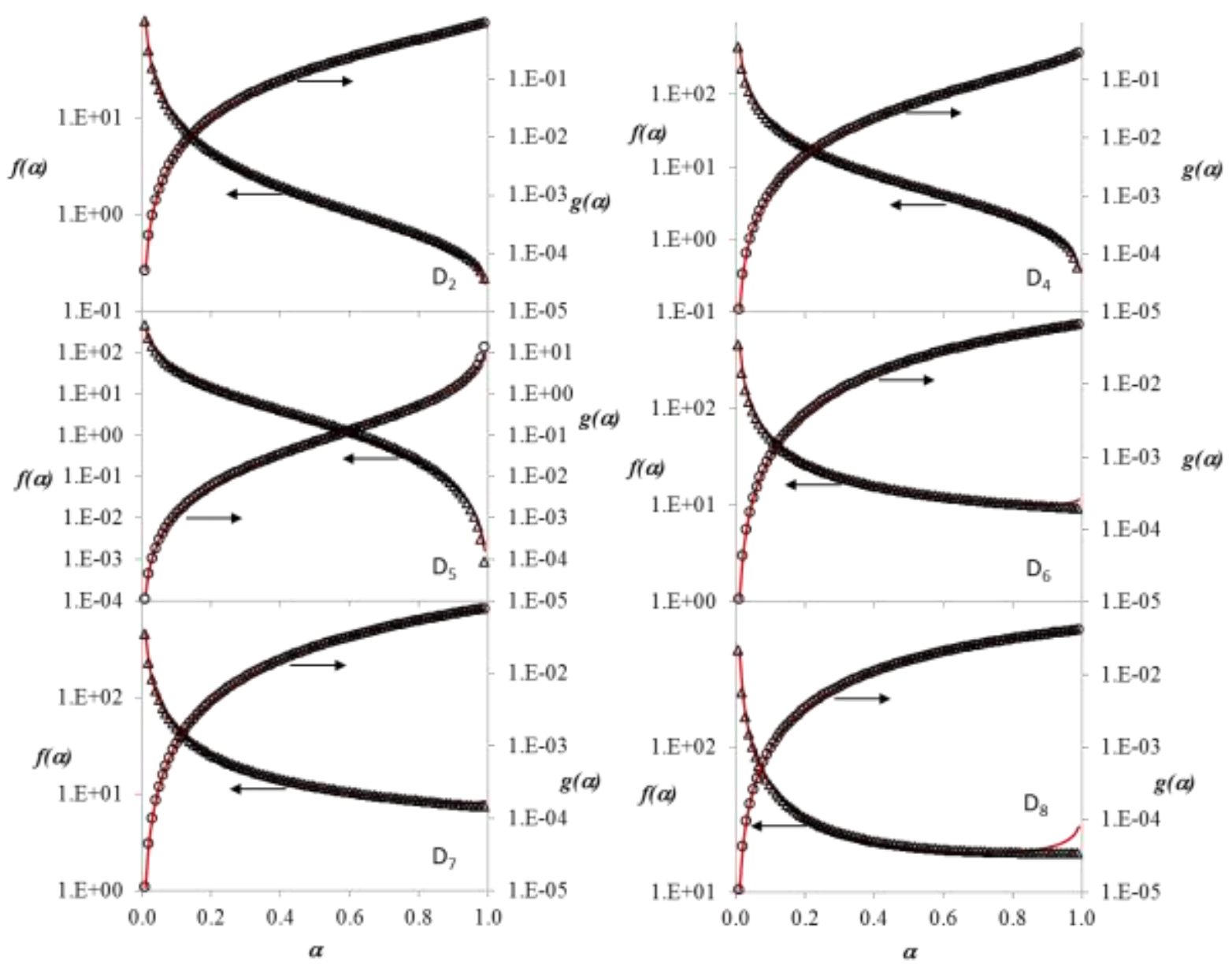

Figure 3 


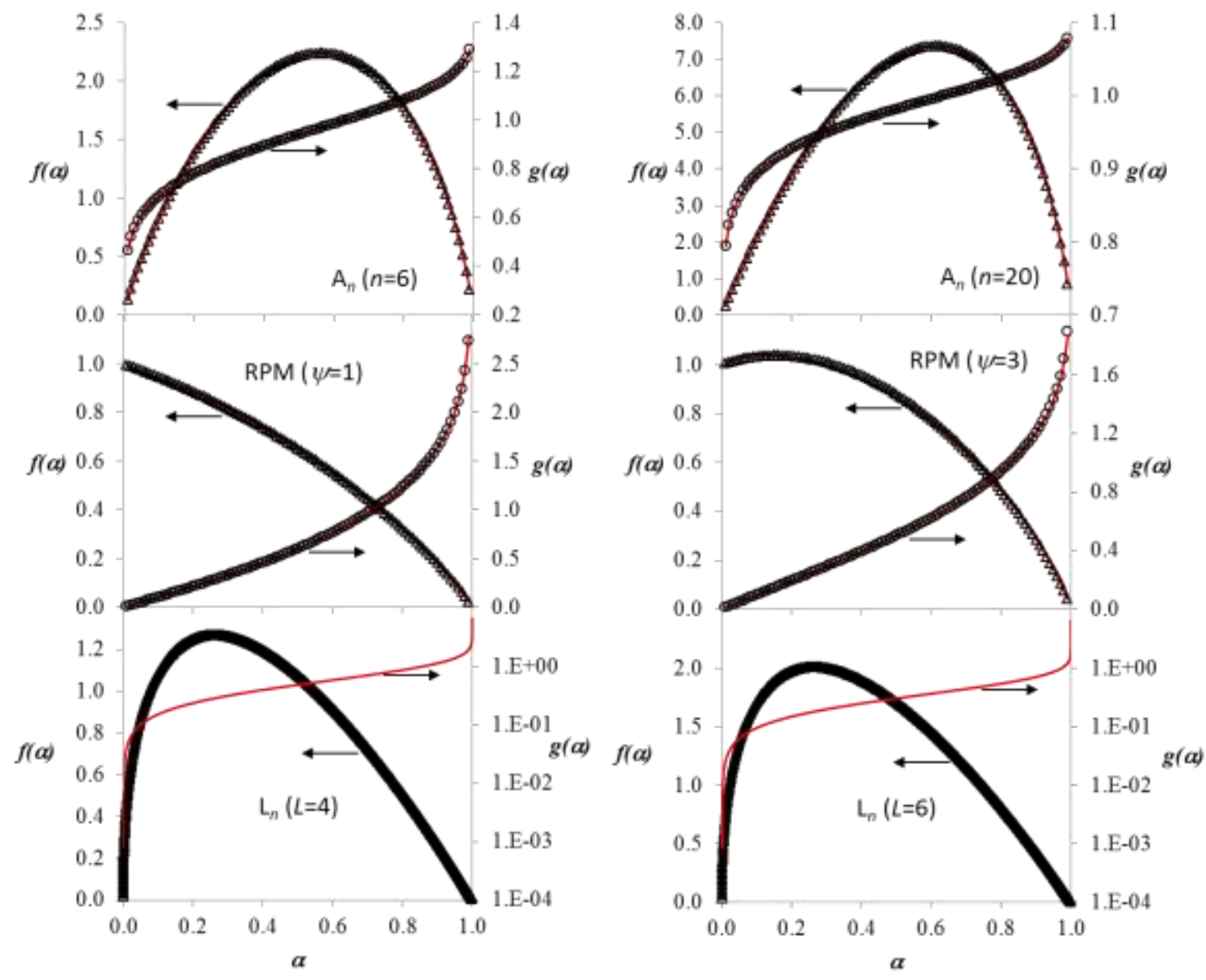

Figure 4 


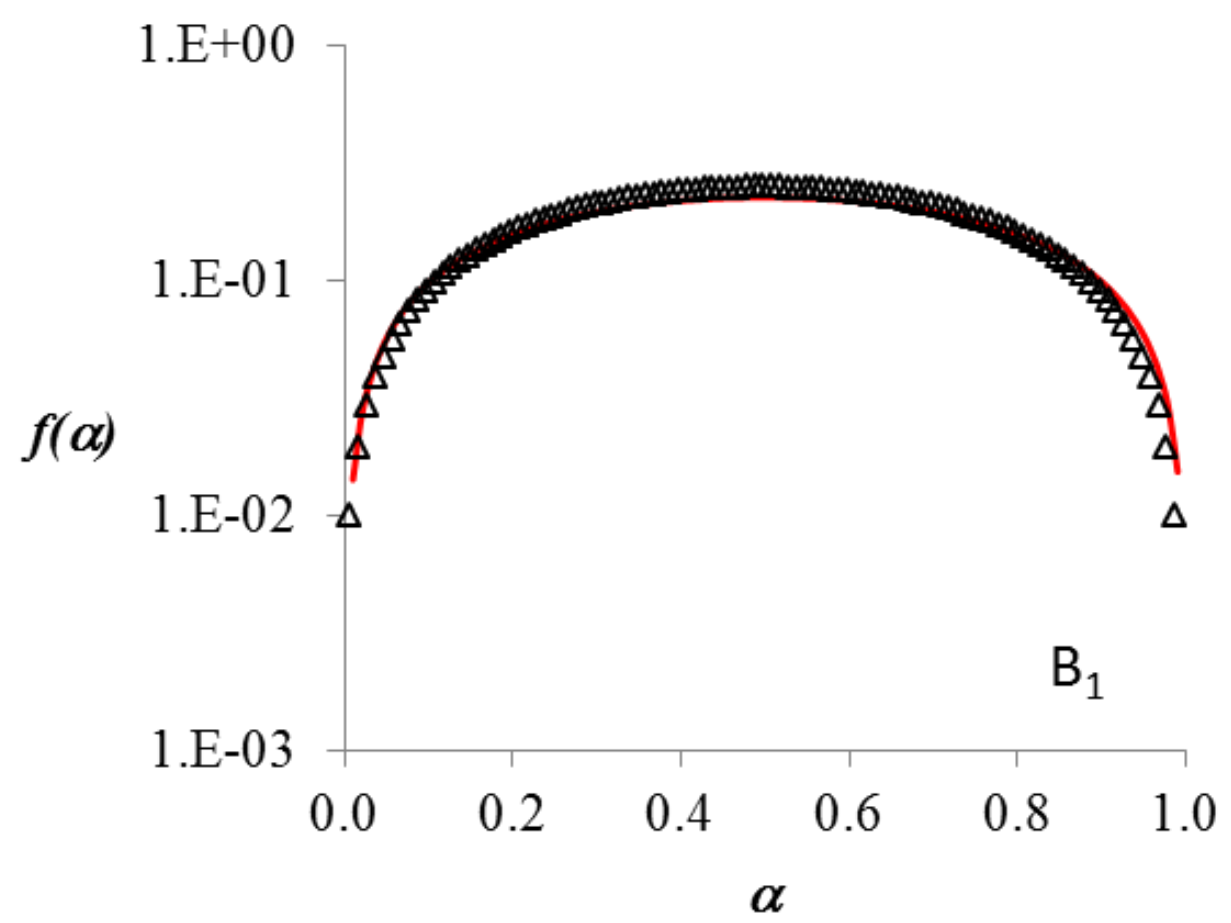

Figure 5 

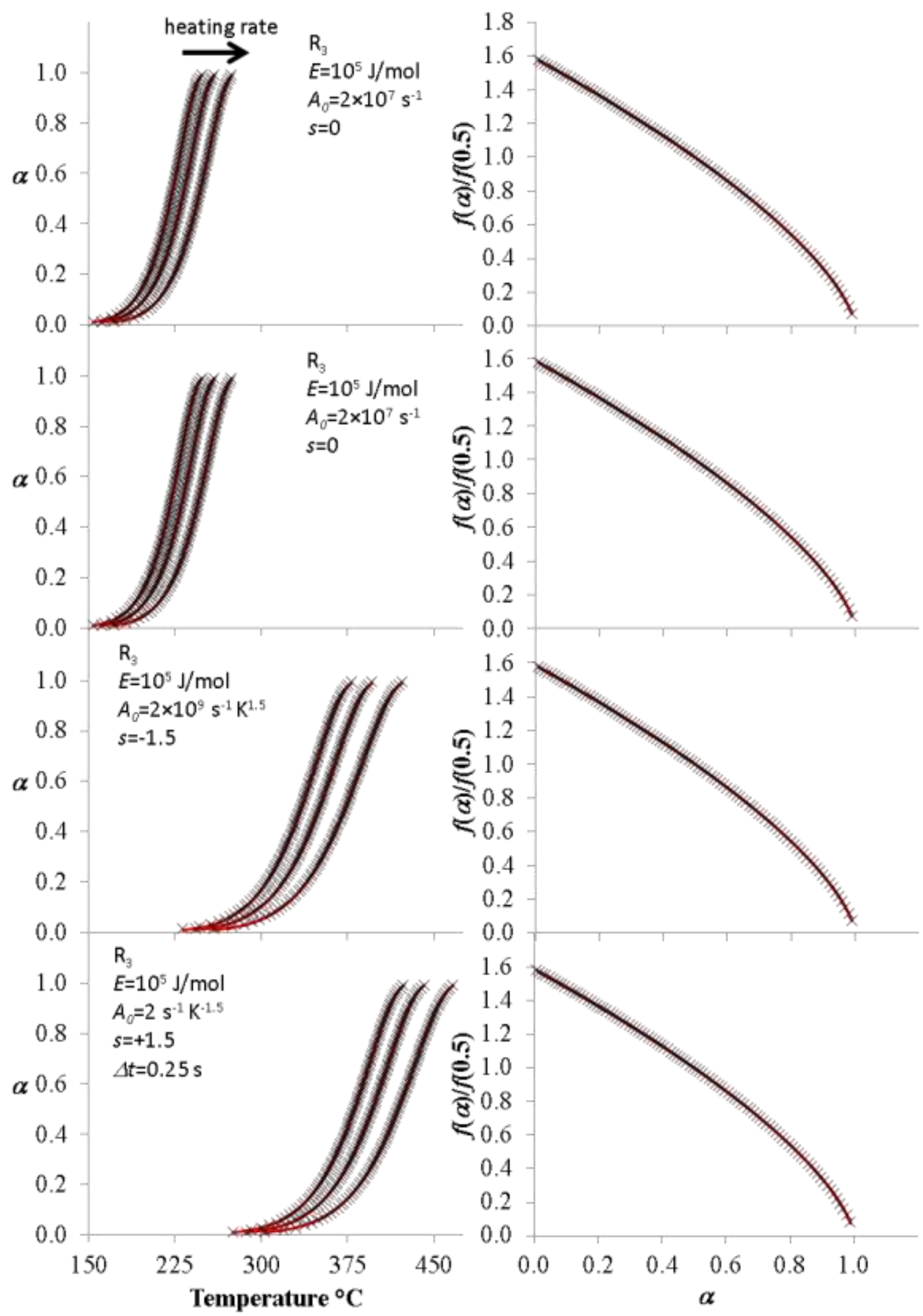

Figure 6 

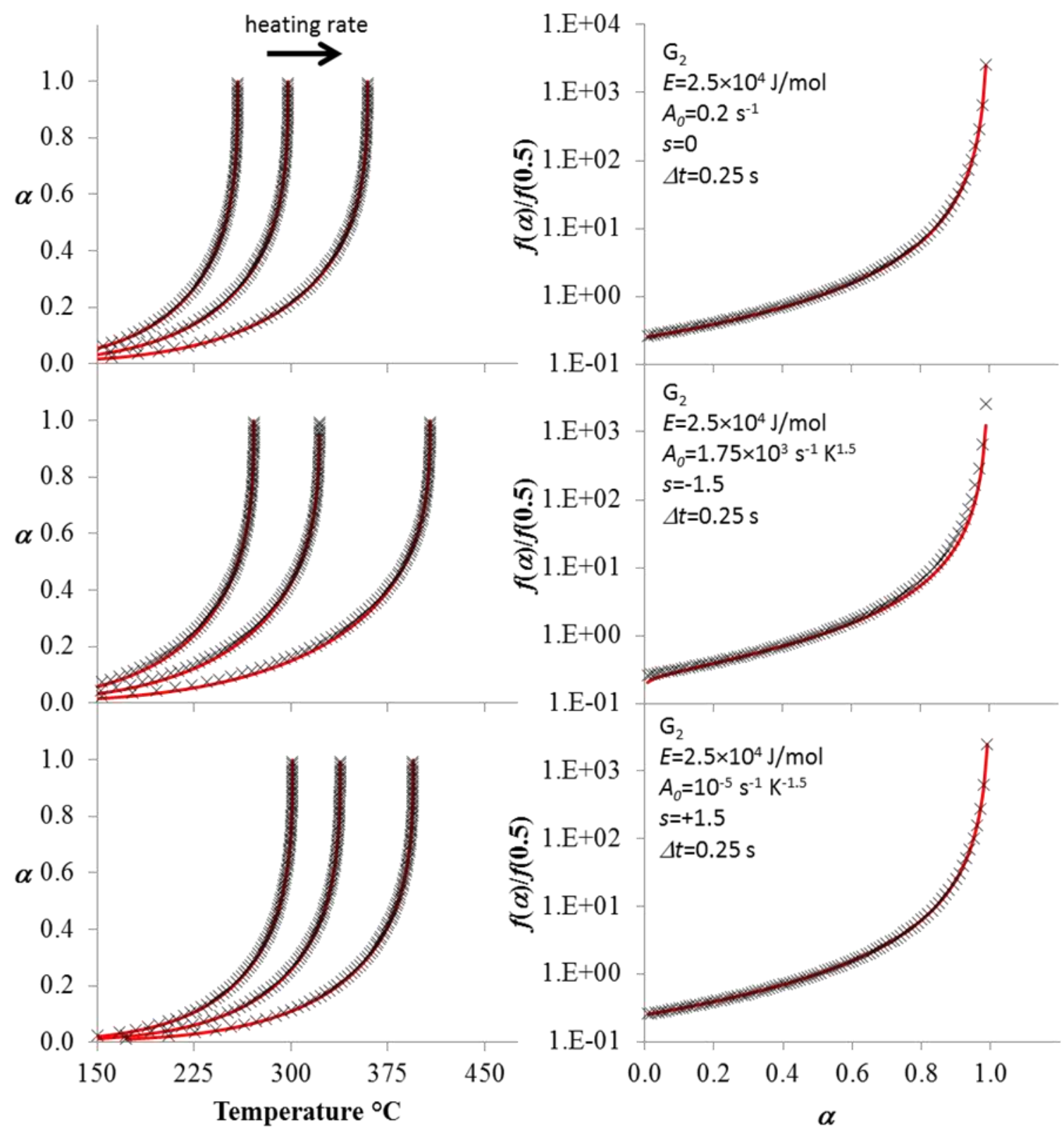

Figure 7 


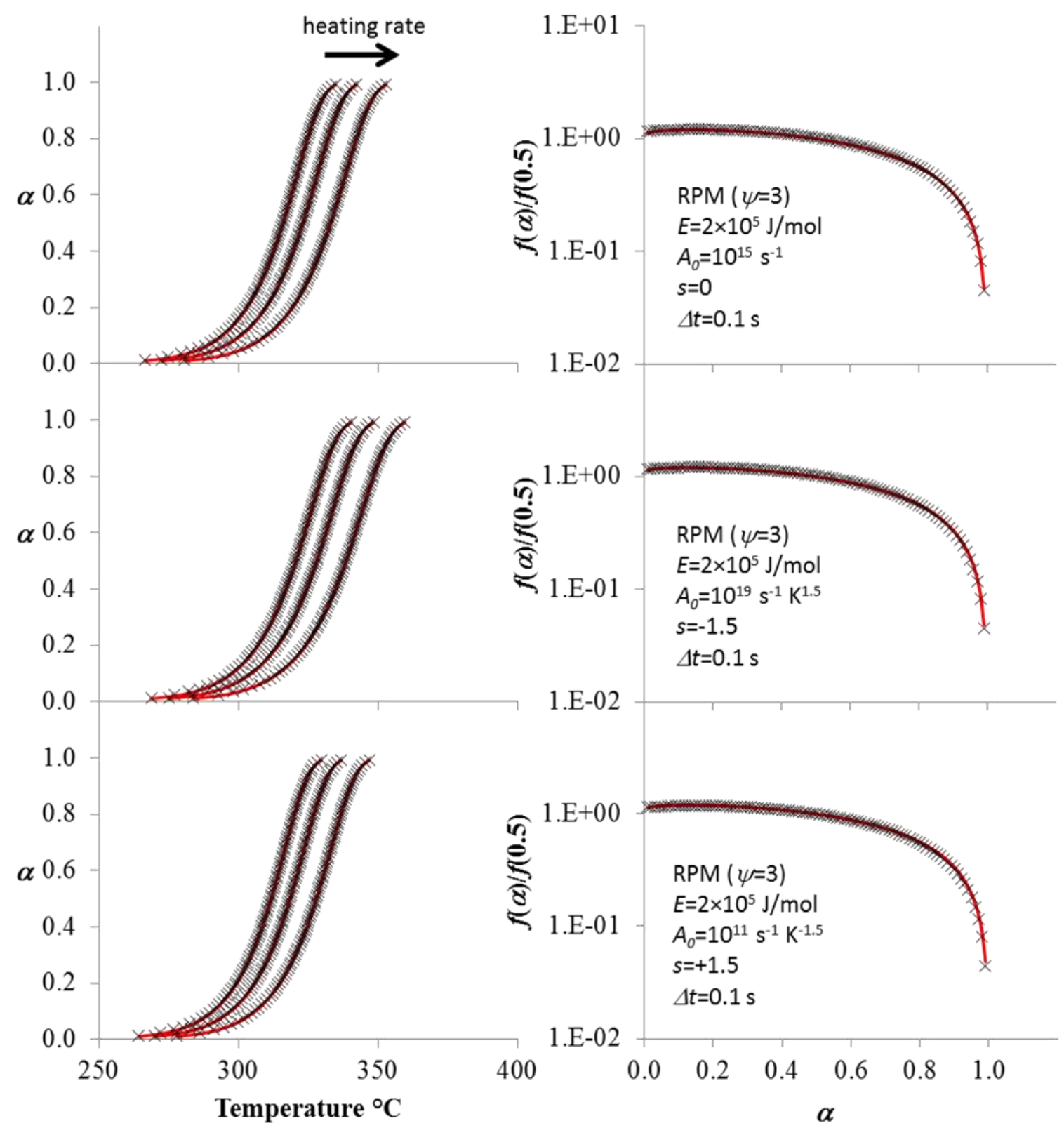

Figure 8 